\title{
Velocity and Sediment Concentration Measurements over Bedforms in Sand-Bed Rivers
}

\author{
Robert R. Holmes, Jr. ${ }^{1}$ and Marcelo H. Garcia ${ }^{2}$
}

\begin{abstract}
Bedforms often are present on the bed of alluvial sand-bed rivers. Bedforms, such as dunes, impact the flow field. In this field study, velocity and suspended-sediment concentration measurements were made longitudinally along a dune field in large (5-15 meters deep) alluvial sand-bed rivers. The velocity and suspended-sediment concentration data was collected using an acoustic Doppler current profiler, acoustic Doppler velocimeters, an optical backscatter sensor, and two sediment intakes. This paper presents a description of these measurement devices and techniques for the collection of this data. Some preliminary results observed at the Missouri River at St. Charles, Missouri are presented.
\end{abstract}

\section{INTRODUCTION}

In alluvial sand-bed rivers, bedforms often are present on the bed. These bedforms are complex and dynamic, and appreciably affect the overall flow field. The flow over a field of bedforms, such as dunes, is more complex than in plane-bed situations. The dunes are an obstacle to the flow and cause both wake effects downstream of the dune and topographically induced spatial acceleration of the flow. In a general longitudinal sense, dunes cause a momentum defect that diffuses outward in the downstream direction. Flow separation occurs near the dune crest followed by a reattachment of the flow on the next downstream dune. At the reattachment point, a new internal boundary layer begins to grow within the wake region. Characterization of the flow field and sediment concentration over bedforms has been investigated mainly in laboratory environments, primarily because of the difficult logistics and expense of collecting field data, particularly on large rivers (depths from approximately 5 to 15 meters).

With the availability of accurate global positioning systems, digital sonar, and acoustic velocity meters, field measurements are easier and more practical to make than in the past. A field study is being conducted in alluvial sand-bed rivers where velocity and sediment concentration over a dune field are being collected both in the near-bed region ( $<1$ meter from the bottom) as well as the outer region of the flow depth. A retrofitted U.S. P-61 suspended-sediment sampler with two acoustic Doppler velocimeters (ADVs), two water intakes, an optical backscatter sensor (OBS), and a compass/tilt/roll sensor (to determine orientation of the ADVs), was constructed to collect near-bed data. The ADVs are used to measure velocity at points in the near-bed region at a sufficient rate (25 Hertz) to resolve some turbulence properties (including Reynolds stresses). The two water

\footnotetext{
${ }^{1}$ Supervisory Hydrologist, U.S. Geological Survey, Urbana, Illinois

${ }^{2}$ Siess Professor and Director, Ven Te Chow Hydrosystems Laboratory, University of Illinois at UrbanaChampaign, Illinois
} 
intakes, along with the OBS sensor, are used to collect information on the suspendedsediment concentration and particle-size distribution. A down-looking acoustic Doppler current profiler (ADCP) was positioned at the water surface to collect velocity data in the outer region of the flow profile (from approximately 3 percent of the flow depth above the bed to near the water surface) along the same vertical as the retrofitted P-61. The ADCP was used also to estimate sediment concentration, utilizing a relationship developed from the sediment concentration determined from the water samples collected at the intakes and the ADCP backscatter at the intake location.

This paper presents an overview of the measurement devices, experimental setup and a few preliminary results of the data collected at the Missouri River at St. Charles, Missouri. Results from this study should add to the understanding of flow and sediment concentration over bedforms particularly in the near-bed region.

\section{BACKGROUND}

Knowledge of the velocity profile is important in many hydraulic engineering applications. The velocity in wall-bounded flow is characterized by a momentum transfer towards the wall from zones of non-perturbed flow. Although it was realized as early as the $4^{\text {th }}$ century B.C. by Aristotle that flow resistance was important to the bulk flow (Rouse and Ince, 1963), it was not until Prandtl (1904) presented his paper on boundary layer theory that fluid mechanics was incorporated into flow-resistance theory. Incorporating this theory enabled a characterization of the velocity-distribution profile in the vertical (Yen, 1992). Alluvial channels add a layer of complexity to any investigation into the flow field because of the ability of the boundary geometry to change with flow condition. In turn, those bedforms modify the flow adjacent to the wall. In experimental observations, it has been noted that in flow over a train of bedforms, a definitive momentum defect region is observed (Nelson and others, 1993; Bennett and Best, 1995). The region is associated with flow separation and wake formation downstream of the bed form lee face and as the wake is advected downstream, the effect of the moment defect is diffused outward, causing the region to grow in depth. Flow characteristics over a dune as part of a laboratory experiment is shown in figure 1 (Nelson and others, 1993). The flow separates at the dune crest and reattaches at some point downstream on the next

dune. This flow over the dunes creates an adverse pressure gradient $\left(\left.\frac{\partial^{2} u}{\partial y^{2}}\right|_{y=0}=\frac{1}{\mu} \frac{d p}{d x}>0\right)$ that causes a smaller velocity gradient and, thus, a smaller velocity near the bed. The reduction in velocity at the bed in the presence of these adverse pressure gradients is well demonstrated in figure 1. 

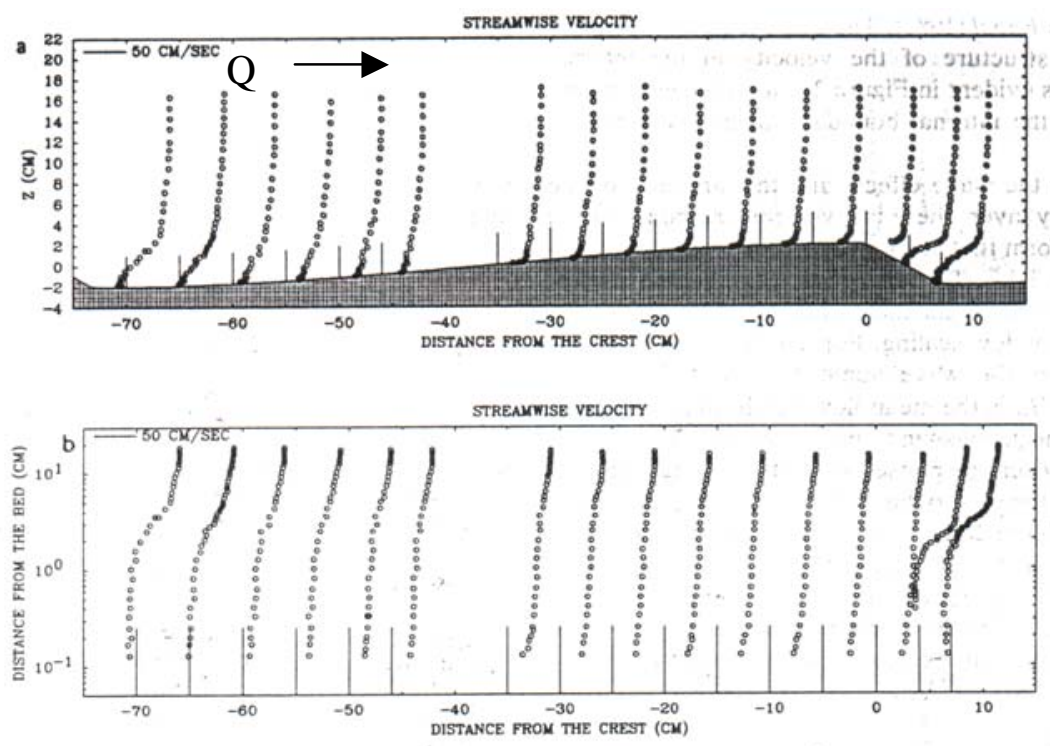

\section{Figure 1. - Observations of velocity distribution along a dune plotted both in both linear and log space (modified from Nelson and others (1993))}

For alluvial channels with bedforms, the flow resistance often is partitioned into form resistance and grain resistance; consequently, the total shear stress is partitioned into grain stress $\left(\tau_{\mathrm{s}}\right)$ and form stress $\left(\tau_{\mathrm{f}}\right)$. This partitioning is important when considering sediment transport, as the grain resistance is the main component responsible for the motion of the sediment grains.

The flow velocity distribution near the wall in channels and conduits is well represented by

$$
\frac{u}{u_{*}}=\frac{1}{\kappa} \ln y+C,
$$

where $\mathrm{u}$ is the time-averaged velocity at location $\mathrm{y}$ in the vertical, $\mathrm{u} *$ is the shear velocity, $\kappa$ is von Karman's constant, and C is a constant (Keulegan, 1938; Schlicting, 1979; Julien, 1995). The velocity profile in a plane bed open-channel flow typically is approximated with one logarithmic equation for the entire flow depth (Keulegan, 1938), with Reynolds stresses typically decreasing monotonically away from the boundary. Nezu and Nakagawa (1993) contend that this logarithmic law relationship is only valid in the wall region $(\mathrm{y} / \mathrm{H}<0.2$, where $\mathrm{H}$ is flow depth) and that there is a deviation away from the log law outside this wall region that should be described using the wake function as developed by Coles (1956). With dunes present, the velocity profile and Reynolds stress profiles have been shown experimentally to be different from that found in plane bed situations (Bennett and Best, 1995; Nezu and Nakagawa, 1993). The velocity profiles for these experiments were logarithmic when averaged in the streamwise direction; however, the slopes vary in at least two separate distinct layers. The separation point between the layers corresponds to a maximum in the Reynolds stress, where the Reynolds stress 
increases from the boundary to the maxima and then decreases toward the water surface (Figure 2). Fedele and Garcia (2001) refer to this as the equilibrium or reference layer and postulate that the maximum shear stress corresponds to the form stress $\left(\left(\tau_{\mathrm{f}}\right)\right.$, while an extrapolation of the Reynolds stresses to the bed is an estimate of the grain stress $\left(\tau_{\mathrm{s}}\right)$.

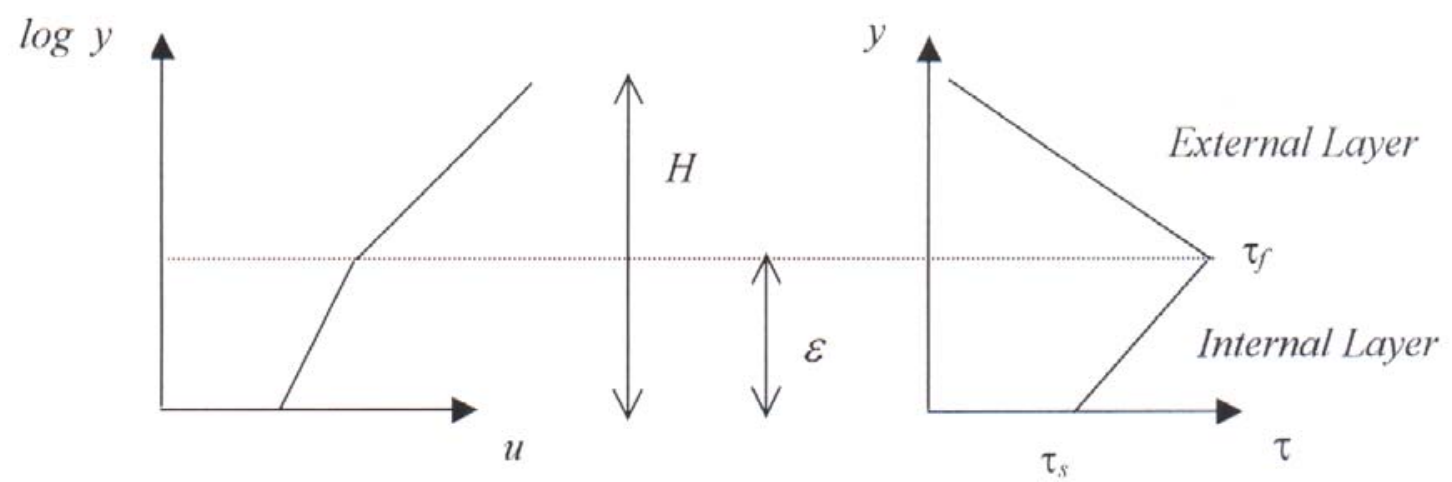

Figure 2.---Velocity profile and spatially averaged Reynolds stress profile (Fedele and Garcia,2001)

Numerous investigations of the flow and sediment concentrations over bedforms have been completed. However, with the notable exception of that of Smith and Mclean (1977), most investigations have been either laboratory studies or involved measured velocities in the far field area away from the bed. Obviously, scale effects need to be considered when theory or algorithms derived from laboratory research are applied to large alluvial rivers (depths 5 to 15 meters or greater). In addition, the knowledge of the processes that occur in the near-bed vicinity is minimal and much is not understood. There is a need for detailed velocity and sediment concentration data on large alluvial rivers to establish means for either enhancing existing theories (utilizing the laboratory data) or producing entirely new theory.

\section{EXPERIMENTAL METHODS}

Velocity and sediment concentration profiles are determined at 10 to 20 locations along a bedform, using measuring equipment suspended from a boat (Figure 3). Using a $200 \mathrm{kHz}$ transducer and GPS, the channel bathymetry was determined. Once a suitable bedform was located, the boat was anchored at the upstream end of the bedform. While the boat remains relatively stationary, velocity and suspended-sediment concentrations are measured at several points along the vertical. After a suitable time of data collection, the anchor lines are played out to re-position the boat at another location along the bedform. This process is repeated until the beginning of the next bedform (in the lee of the bedform). 

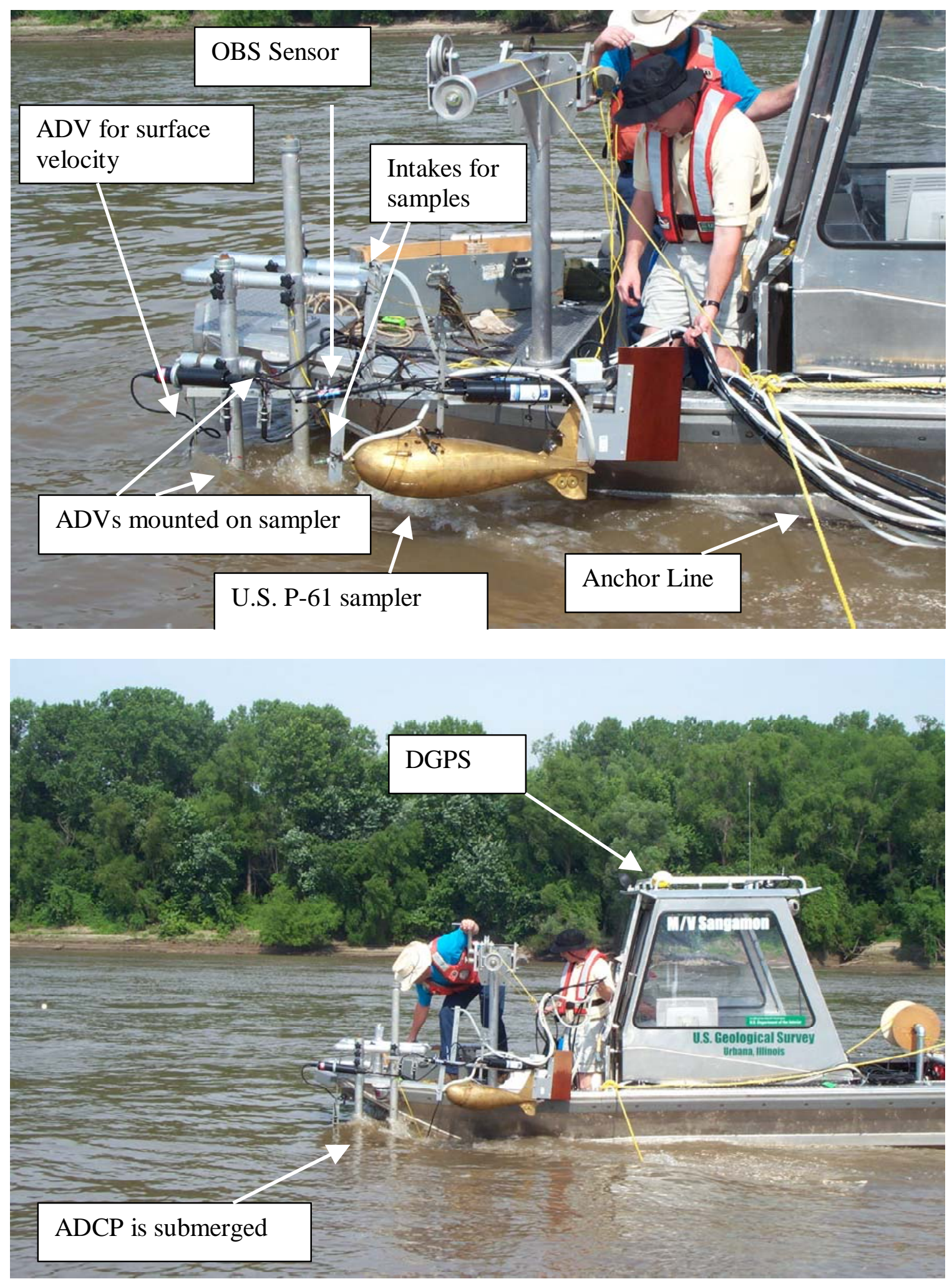

Figure 3.-Boat anchored preparing to collect data on the Missouri River at St Charles, Missouri 


\section{EQUIPMENT AND INSTRUMENTATION}

The ADCP is mounted in a down-looking position (figure 3) and provides 3-D velocities from below the water surface (typically from 0.6 to 1.2 meters below the water surface, depending on settings used in the ADCP) to within 3 to 6 percent of the flow depth at the bottom. An ADV also is mounted on the boat to provide a 3-D velocity within 0.25 meter of the surface. A retrofitted U.S. P-61 sediment sampler was equipped with a mounting frame that accommodates 2 ADV's, 2 sampler intakes, and 1 OBS sensor to collect data in the near-bed region ( $<1$ meter from bed) (figure 4). The P-61 is lowered from a crane on the boat to the bed of the river. ADV orientation is determined with a submersible compass/tilt/roll sensor mounted on the P-61. The sampler intakes are connected via tubing to a pump in the boat. The uppermost water sample intake is located at a distance above the bed in which the ADCP still can resolve the flow velocity and signal backscatter. Using the backscatter data reported by the ADCP for this location, a relation between suspended-sediment concentration and ADCP backscatter is estimated. This relation is applied to the backscatter values in the other "bins" reported by the ADCP to estimate the suspended-sediment concentration at these locations. The OBS sensor is located at the same location as the other water sample intake. Samples collected at this location are used to calibrate the OBS sensor.

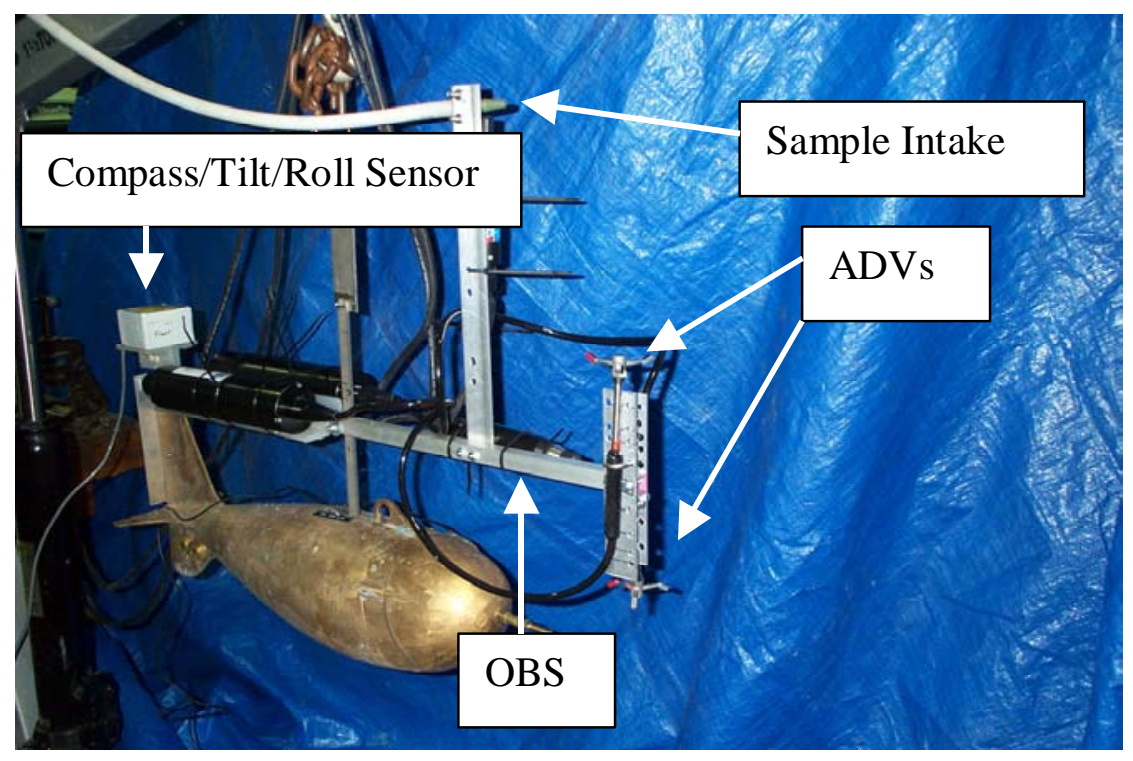

Figure 4.-Modified U.S. P-61 to accommodate ADV and OBS sensors and sampler intakes

The ADV, manufactured by Nortek, is a $10 \mathrm{MHz}$ remote-sensing, three-dimensional velocity sensor. ADV operation is based on the Doppler shift effect and is capable of collecting data at $25 \mathrm{~Hz}$. The ADV is a bi-static (focal point) acoustic Doppler system and consists of a transmitter and three receivers. The sampling volume is approximately 
$5 \mathrm{~cm}$ from the probe. ADV's often are used to make turbulence measurements and can measure Reynolds stresses and mean velocity very accurately, even up to $1 \mathrm{~cm}$ from the bed for mean velocity and $3 \mathrm{~cm}$ for Reynolds stresses (Voulgaris and Trowbridge, 1998). The ADCP used in the research is a $600 \mathrm{kHz}$ unit manufactured by RDI. The ADCP has a maximum measurement frequency of $5 \mathrm{~Hz}$ with single ping (no averaging of signals) data, however, the data in this study is recorded at around $3 \mathrm{~Hz}$. There is a blanking distance in the first $25 \mathrm{~cm}$ of flow because of signal ringing and side lobe interference causes bias of the velocity measurements near the bed and distance affected is dependent on the flow depth (3 to $6 \%$ of depth), therefore, the ADCP cannot resolve the flow velocity for the entire flow depth. Nystrom and others (in press) found that the Rio Grande ADCP had as little as $2 \%$ error for determination of mean velocity in low turbulence flow $\left(<\sqrt{\overline{u^{\prime 2}}}<2 \mathrm{~cm} / \mathrm{sec}\right)$. Also, they found that turbulence intensities were biased high in both the streamwise and vertical directions; in some cases, intensities were biased by $130 \%$ (or $2 \mathrm{~cm} / \mathrm{sec}$ ) in the streamwise direction, but they conclude that bias maybe correctable because of its predictability.

Because of the spread of the beam signals in the ADCP, there is some spatial averaging of the velocities, as all four beams are used to compute the velocity at the particular depth (referred to as depth cells or bins). An anchored boat is subject to pitch, roll, heading, and translation. These motions will cause more spatial averaging of velocity than if the ADCP were deployed from a fixed platform. Gonzalez and others (1996) assumed that for a wide channel where 2-D flow essentially could be assumed, that turbulence at a particular depth location approximately is equal in the lateral direction, thus averaging of flow velocities in space and time for a given depth should result in reasonable mean velocity profiles.

The retrofitted U.S. P-61 sampler was placed in the large flume (1.8 meters wide) at the University of Illinois Ven Te Chow Hydrosystems Laboratory in Urbana-Champaign. The first version of the sampler was found to cause a 7 percent increase in flow velocity over the ambient stream velocity at water velocities of around $40 \mathrm{~cm} / \mathrm{sec}$. The frame on the sampler then was modified to move the ADV farther forward from the body of the U.S. P-61 to minimize these acceleration effects.

\section{Field Experiments and Preliminary Data}

Data were collected on June 19, 2002 on the Missouri River at St. Charles, Missouri. Flow depths ranged from 5.5 to 7 meters with surface flow velocities ranging from 130 $\mathrm{cm} / \mathrm{sec}$ to $170 \mathrm{~cm} / \mathrm{sec}$. Dunes on the Missouri River were approximately 1 to 2 meters high and 25 to 40 meters long. Preliminary velocity profiles collected at 20 points along a dune train are presented in figure 6 . One ADV was mounted 0.2 meters off the port bow (figure 3 ) and 0.25 meters below the water surface. Because of the boat draft $(0.46$ meters) and the necessity to keep the boat at an angle to the flow (to prevent the cable from coming off the pulley), the ADV velocities were found to be biased low (and not useable) by as much as 0.5 meters per second because of the disturbance to the flow field caused by the boat form. A cursory comparison of figures 1 and 5 reveal similarities in 
the velocity profiles along the dune, complete with the wake effects in the lee of the dune and the appearance of boundary layer growth.

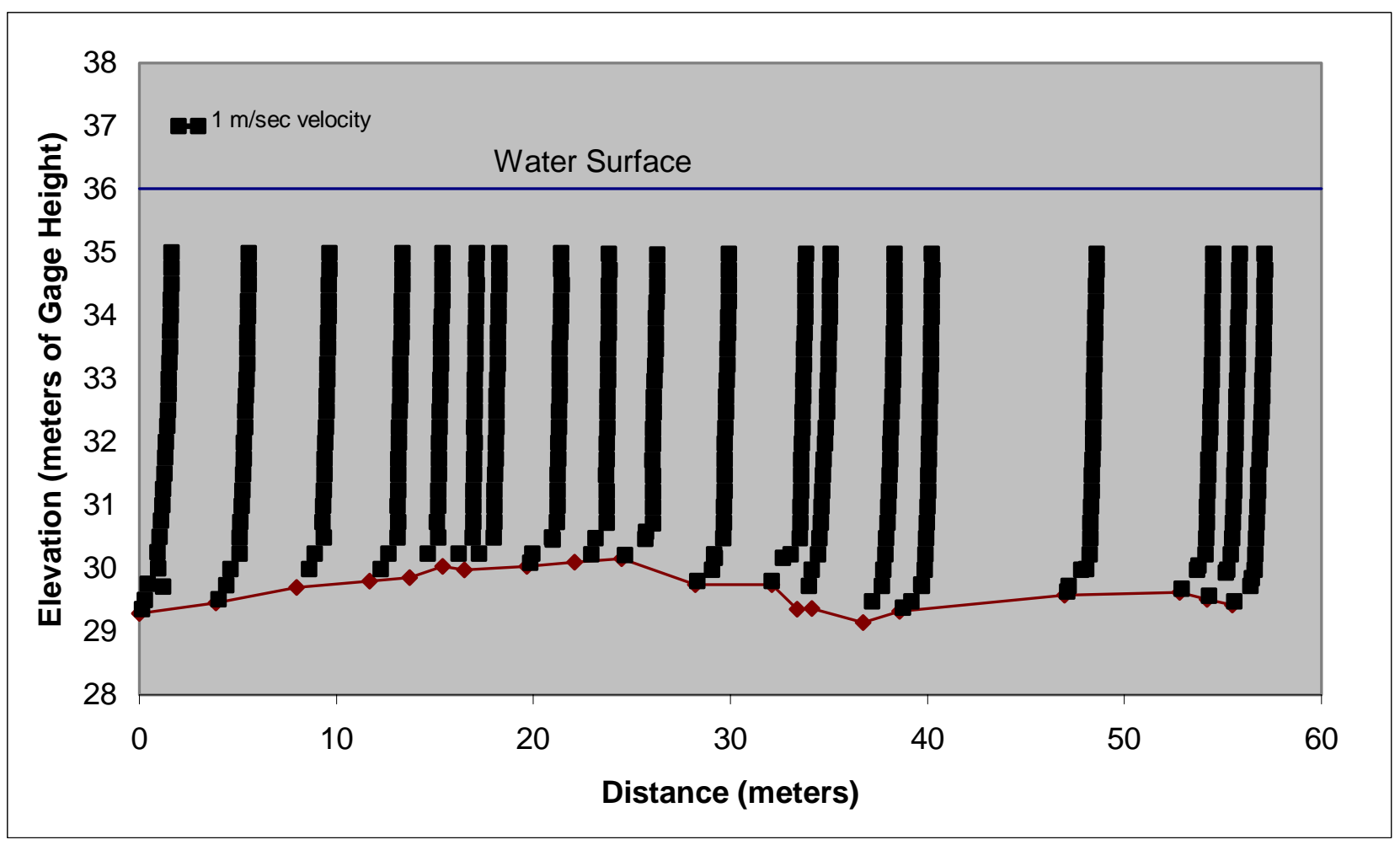

Figure 5.-- Observations of velocity distribution along a dune for the Missouri River at St Charles, Missouri (June 19, 2001; Flow Rate of 3,170 cubic meters per second)

\section{References}

Bennett, S.J. and Best, J.L., 1995, Mean flow and turbulence structure over fixed, twodimensional dunes: implications for sediment transport and bedform stability, Sedimentology, Vol. 42, pp 491-513

Coles, Donald, 1956, The law of the wake in the turbulent boundary layer, Journal of Fluid Mechanics, Vol. 1, pp 191-226

Fedele, J.J. and Garcia, M.H., 2001, Alluvial roughness in streams with dunes: a boundary-layer approach, in River, Coastal and Estuarine Morphodynamics, Giovanni Seminara and Paolo Blondeaux, Ed., Springer, Berlin, pp 37-60 
Gonzalez, J.A., Melching, C.S., and Oberg, K.A., 1996, Analysis of open-channel velocity measurements collected with an acoustic Doppler current profiler, Proceedings from the $1^{\text {st }}$ International Conference on New/Emerging Concepts for Rivers, International Water Resources Association, September 22-26, 1996, Chicago, Illinois, pp 838-845

Julien, P.Y., 1995, Erosion and Sedimentation, Cambridge University Press, 280 p.

Nelson, J.M., McLean, S.R., and Wolfe, S.R., 1993, Mean flow and turbulence fields over two-dimensional bed forms, Water Resources Research, Vol. 29, No. 12, pp 39353953.

Nezu, Iehisa and Nakagawa, Hiroji, 1993, Turbulence in open-channel flows, IAHR Monograph Series, A.A. Balkema Publishers, Rotterdam, Netherlands, 281 p.

Nystrom, E.A., Oberg, K.A., and Rehmann, C.R., In Press, Measurement of mean velocity and turbulence with ADCP's, submitted to ASCE Journal of Hydraulic Engineering

Prandtl, Ludwig, 1904, Ueber Flussigkeitsbewegung bei sehr kleiner Reibung, Proceedings $3^{\text {rd }}$ International Congress of Mathematics, Heidelberg, pp 484-491

Rouse, Hunter and Ince, S, 1963, History of Hydraulics, Dover Publications, New York

Schlicting, Hermann, 1979, Boundary-layer theory, $7^{\text {th }}$ Edition, McGraw-Hill Books, New York, 817 p.

Smith, J.D. and Mclean, S.R., 1977, Spatially averaged flow over a wavy surface, Journal of Geophysical Research, Volume 82, Number 12, pp 1735-1746.

Voulgaris, G. and Trowbridge, J.H., 1998, Evaluation of the acoustic Doppler velocimeters (ADV) for turbulence measurements, Journal of Atmospheric and Oceanic Technology, Vol. 15, pp 272-289

Yen, B.C., 1992, Hydraulic Resistance in Open Channels, in Channel Flow Resistance: Centennial of Manning's Formula, B.C. Yen, ed., Water Resources Publications, Littleton, Colorado, pp 1-135 